\title{
In vivo assessment of lung inflammatory cell activity in patients with COPD and asthma
}

\author{
H.A. Jones, P.S. Marino, B.H. Shakur, N.W. Morrell
}

In vivo assessment of lung inflammatory cell activity in patients with COPD and asthma. H.A. Jones, P.S. Marino, B.H. Shakur, N.W. Morrell. (C)ERS Journals Ltd 2003.

ABSTRACT: The involvement of inflammatory cells in the pathogenesis of chronic obstructive pulmonary disease (COPD) and asthma is well established. This study aimed to quantify differences in inflammatory cell function in situ in these patients as compared to normal subjects.

Positron emission tomography was used to assess neutrophil activity $\left({ }^{18} \mathrm{~F}\right.$-fluorodeoxyglucose $\left({ }^{18}\right.$ FDG ) and macrophage accumulation $\left({ }^{11} \mathrm{C}\right.$-PK11195) in six patients with COPD, six chronic asthmatics and five age-matched normal control subjects.

${ }^{18}$ FDG uptake was greater in COPD than in normal subjects, with no increase in asthmatics. The mean slope of ${ }^{18}$ FDG uptake, corrected for volume of distribution, was 4.0 $\mathrm{min}^{-1}$ in COPD patients compared with $1.5 \mathrm{~min}^{-1}$ in control subjects and $1.7 \mathrm{~min}^{-1}$ in asthmatics. Mean ${ }^{11} \mathrm{C}$-PK11195 uptake (plateau tissue:plasma) was higher in four of six COPD patients (10.8) and three of five asthmatics (11.8) than the maximum value in control subjects (6.2).

From this preliminary study the authors conclude that positron emission tomography may be useful to assess polymorphonuclear neutrophil and macrophage activity in vivo in chronic obstructive pulmonary disease and asthma, and may reveal differences in cell behaviour between the study groups. In addition, positron emission tomography may provide indices of disease activity for future therapeutic studies. Eur Respir J 2003; 21: 567-573.
Division of Medicine and National Heart and Lung Institute, Faculty of Medicine, Imperial College, London, UK.

Correspondence: H.A. Jones, Respiratory Medicine, National Heart and Lung Institute, Faculty of Medicine, Imperial College London, Hammersmith Campus, London W12 0NN, UK

E-mail: hazel.jones@ic.ac.uk

Fax: 442087439733

Keywords: ${ }^{18}$ F-fluorodeoxyglucose, neutrophils, macrophages, PK11195, positron emission tomography

Received: June 62002

Accepted after revision: October 212002

This study was funded by a Research Donation from GlaxoSmithKline, UK.
Chronic obstructive pulmonary disease (COPD) leads to major morbidity and mortality as a consequence of loss of lung function [1]. Asthma is an increasingly common disease responsible for time off work and reduced quality of life [2]. Both diseases have an inflammatory component [3, 4]. Difficulties in monitoring the pathogenic processes involved in the progression of lung disease in vivo have hampered the design and study of therapeutic interventions. Lung biopsy is invasive, difficult to repeat and may not be representative if disease distribution is heterogeneous. Chest radiographs show changes in lung density but give no indication of disease activity. High-resolution computed tomography assesses lung architecture but does not enable monitoring of inflammatory cell behaviour. Lavaging lung segments for inflammatory cells during bronchoscopy accesses only the airspaces when the disease process may be largely in the interstitium.

External imaging of intravenously injected radiolabelled markers of inflammatory processes has a great potential for providing noninvasive and repeatable methods of monitoring inflammatory cell behaviour, allowing the whole lung to be studied in situ. Gamma-scintigraphy of indium 111-labelled granulocytes can be used to monitor migration of cells into the lungs [5], but not their metabolic activation [6]. Positron emission tomography (PET) enables quantification of radioactivity throughout the lungs, in airspaces and interstitium, enabling study of the behaviour of key inflammatory cells in their native micro-environment.

The current authors have already successfully used positron emission imaging following injection of ${ }^{18} \mathrm{~F}$-fluorodeoxyglucose $\left({ }^{18} \mathrm{FDG}\right)$ to monitor neutrophil metabolic activity in vivo [7] and have shown dissociation between migration and activation of these cells in pneumonia and bronchiectasis [6]. The authors have also shown that chronic activation of neutrophils is associated with the development of pulmonary fibrosis and structural changes [8]. The authors have recently shown in vitro that the uptake of deoxyglucose by neutrophils reflects both priming and activation [9]. This sustained neutrophil presence and activation is likely to be orchestrated by pulmonary alveolar and interstitial macrophages. Accumulation of macrophages can be measured noninvasively by PET imaging of ${ }^{11} \mathrm{C}$-labelled PK11195 uptake, as the authors have demonstrated in rabbit lungs in response to particulate challenge [10].

In this study, ${ }^{18}$ FDG and the ligand ${ }^{11} \mathrm{C}-\mathrm{PK} 11195$ have been employed as markers to study neutrophil and macrophage behaviour in situ by PET, in well-characterised groups of patients with COPD or asthma, compared to age-matched normal controls.

\section{Methods}

Six COPD patients were selected on the basis of a smoking history ( $>10$ pack-yrs), moderate-to-severe airflow obstruction (forced expiratory volume in one second (FEV1) $<60 \%$ predicted) and a low diffusing capacity for carbon monoxide, suggestive of emphysema [11]. Six patients with chronic asthma were selected on the basis of clinical history of recurrent wheezing accompanied by airflow obstruction, at least partially reversible by salbutamol, and absence of 
Table 1.-Demographical data, smoking history and baseline lung function tests

\begin{tabular}{|c|c|c|c|c|c|c|c|c|c|}
\hline \multirow[t]{2}{*}{ Subject } & \multirow[t]{2}{*}{ Age yrs } & \multirow[t]{2}{*}{ Sex } & \multicolumn{2}{|c|}{ Smoking history } & \multirow[t]{2}{*}{$K \mathrm{CO} \%$ pred } & \multicolumn{4}{|c|}{ Spirometry } \\
\hline & & & Pack-yrs & Exsmoker $^{\#}$ yrs & & $\begin{array}{l}\text { FEV1 } \\
\% \text { pred }\end{array}$ & $\begin{array}{c}\mathrm{VC} \\
\% \text { pred }\end{array}$ & $\underset{\%}{\mathrm{FEV} 1 / \mathrm{VC}}$ & $\begin{array}{l}\mathrm{FEV}_{1} \text { post } \\
\text { bd } \% \text { incr. }\end{array}$ \\
\hline \multicolumn{10}{|l|}{ Normal } \\
\hline 1 & 75 & M & & & 112 & 94 & 102 & 93 & 0 \\
\hline 2 & 77 & M & & & 166 & 78 & 89 & 87 & 0 \\
\hline 3 & 55 & M & & & 109 & 119 & 127 & 74 & 1 \\
\hline 4 & 52 & $\mathrm{~F}$ & & & 109 & 117 & 171 & 79 & -1 \\
\hline 5 & 59 & $\mathrm{M}$ & & & 132 & 100 & 100 & 77 & 1 \\
\hline Mean & 64 & & & & 126 & 102 & 118 & 82 & 0 \\
\hline \multicolumn{10}{|l|}{ COPD } \\
\hline 1 & 73 & M & 41 & 17 & 51 & 42 & 119 & 35 & 8 \\
\hline 2 & 60 & $\mathrm{~F}$ & 60 & 1 & 71 & 47 & 104 & 38 & 6 \\
\hline 3 & 78 & $\mathrm{M}$ & 70 & 3 & 61 & 26 & 78 & 25 & -16 \\
\hline 4 & 68 & M & 36 & 2 & 52 & 30 & 105 & 29 & 7 \\
\hline 5 & 64 & M & 75 & 1 & 74 & 46 & 88 & 32 & -4 \\
\hline 6 & 79 & $\mathrm{~F}$ & 55 & 8 & 69 & 51 & 98 & 52 & 1 \\
\hline Mean & 70 & & 56 & 5 & 63 & 40 & 99 & 35 & 0 \\
\hline \multicolumn{10}{|l|}{ Asthma } \\
\hline 1 & 62 & $\mathrm{~F}$ & & & 143 & 57 & 71 & 67 & 12 \\
\hline 2 & 57 & M & & & 148 & 36 & 41 & 69 & 20 \\
\hline 3 & 54 & $\mathrm{~F}$ & & & 184 & 55 & 76 & 61 & 24 \\
\hline 4 & 65 & $\mathrm{~F}$ & & & 121 & 67 & 66 & 70 & 13 \\
\hline 5 & 66 & $\mathrm{~F}$ & & & 148 & 83 & 91 & 78 & 18 \\
\hline 6 & 54 & $\mathrm{~F}$ & 20 & 19 & 147 & 115 & 107 & 80 & 2 \\
\hline Mean & 60 & & & & 149 & 69 & 75 & 71 & 15 \\
\hline
\end{tabular}

KCO: carbon monoxide transfer coefficient; \% pred: \% predicted; FEV1: forced expiratory volume in one second; VC: vital capacity; bd: bronchodilator; incr.: increase; COPD: chronic obstructive pulmonary disease; M: male; F: female. ${ }^{\#}$ : number of years since stopping smoking.

exposure to cigarettes for $\geqslant 19$ yrs. Five age-matched neversmokers served as controls. Characterisation of all subjects is shown in table 1.

All volunteers gave written and informed consent to enter the study, which was approved by the Research Ethics Committee of Hammersmith, Queen Charlotte's \& Chelsea Hospital and Acton Hospitals (London, UK) and the UK Administration of Radioactive Substances Advisory Committee (Dept of Health). No patients had required oral corticosteroids or antibiotics for 6 weeks before PET scanning.

Each patient refrained from using inhaled medication for $12 \mathrm{~h}$ prior to the study and had fasted for $\geqslant 6 \mathrm{~h}$ (for ${ }^{18} \mathrm{FDG}$ scan only, to reduce circulating blood glucose levels). Each subject was positioned supine with the thorax in the detector ring of the PET scanner (ECAT 931-08/12; Siemens/CTI, Knoxville, TN, USA). Cannulae were placed in the right arm vein for injection of radioisotope and left arm for withdrawal of blood for measurement of radioactivity. Transmission scans were performed by measuring the transmission of radioactivity through the field of view of the PET scanner from a ring source containing ${ }^{68}$ germanium. An initial rectilinear transmission scan was carried out to define the diaphragmatic boundary of the lung and the scanner bed was moved so that the lowest of the 15 transaxial planes measured in the PET scanner was aligned with the dome of the diaphragm. A 20-min transmission scan was carried out for attenuation correction of the subsequent emission scans and for measurement of regional lung density.

For measurement of inflammatory cell metabolic activity, the transmission scan was followed by intravenous infusion of $120 \mathrm{MBq}$ of ${ }^{18} \mathrm{FDG}$ in normal saline over $2.5 \mathrm{~min}$. Positron emission data were acquired dynamically in 16 consecutive frames over $1 \mathrm{~h}$. During the emission scan, venous blood was sampled continuously at $2.5 \mathrm{~mL} \cdot \mathrm{min}^{-1}$ and drawn through a detector for measurement of radioactivity in blood. Discrete samples were taken at intervals to monitor blood glucose levels and, following centrifugation, to measure the whole blood:plasma ratio of radioactivity.

For measurement of macrophages, the transmission scan was followed by inhalation of trace amounts of $\mathrm{C}^{15} \mathrm{O}$ in the air $\left(3 \mathrm{MBq} \cdot \mathrm{mL}^{-1}\right.$ at $\left.500 \mathrm{~mL} \cdot \mathrm{min}^{-1}\right)$ delivered in a loose-fitting face mask over 4 min to label the circulating red cells with ${ }^{15} \mathrm{O}$-labelled carboxyhaemoglobin. Following a 2-min washout of $\mathrm{C}^{15} \mathrm{O}$ from the lung airspaces, emission data was acquired in five 1-min frames to enable calculation of regional thoracic blood volume from image data and radioactivity measured in blood samples. At least 10 min later, after the radioactivity had decayed to background levels $\left({ }^{15} \mathrm{O}\right.$ halflife $=2 \mathrm{~min}$ ), $370 \mathrm{MBq}{ }^{11} \mathrm{C}-\mathrm{R}-\mathrm{PK} 11195$ in saline was injected over $1 \mathrm{~min}$ and ${ }^{11} \mathrm{C}$ activity monitored in 15 consecutive time frames over $30 \mathrm{~min}$. During this second emission scan, radioactivity in venous blood was measured continuously as during the FDG emission scan. The whole blood:plasma ratio of radioactivity was measured in discrete blood samples taken at 10 -min intervals, together with measurement of the ratio of radioactive parent compound:radioactive metabolites.

Following the PET scans, sputum samples were collected from each patient to assess the cell populations present in the airways. Sputum was induced and cytospin slides prepared using previously described methods [12, 13]. In brief, FEV1 and forced vital capacity measurements were recorded before inhalation of salbutamol $200 \mu \mathrm{g}$ by metered-dose inhaler to establish baseline spirometry and, 15 min later, to obtain maximal FEV1 and to minimise the risk of bronchoconstriction during the induction. After inhaling isotonic saline for $1 \mathrm{~min}$, subjects inhaled nebulised hypertonic $(4.5 \%)$ saline from an ultrasonic nebuliser (DeVilbiss 2000; DeVilbiss Co., Heston, UK) for progressively increasing periods $(1,2,4,8$ and up to a 
maximum of $20 \mathrm{~min}$ ). FEV1 was recorded after each inhalation period to monitor any bronchoconstriction. Sputum was processed within $2 \mathrm{~h}$ of start of collection. Viscid or denser portions ("plugs") from the expectorated sample were selected by eye or with the aid of an inverted microscope. To achieve complete homogenisation, dithiothreitol (DTT) (Sputolysin; Calbiochem Corp., San Diego, CA, USA), freshly prepared in a 1:10 dilution with distilled water, equal to four times the weight of the selected portion (in $\mathrm{mg}$ ) of each sputum sample, was added. The DTT/sputum mixture was placed in a shaking water bath at $37^{\circ} \mathrm{C}$ for $20 \mathrm{~min}$. After dilution with phosphatebuffered saline (PBS) to stop further digestion, the sample was filtered through nylon mesh $(48 \mu \mathrm{M})$ to remove any residual mucus, centrifuged at $800 \times g$ for $5 \mathrm{~min}$ and the cell pellet was resuspended in PBS. Total cell count and viability by Trypan blue exclusion were determined with a Neubauer haemocytometer (Weber Scientific International, Teddington, UK). Diluted cell suspension in $100 \mu \mathrm{L}$ aliquots were spun in a cytocentrifuge (Shandon, Runcorn, UK) at $20 \times g$ for 6 min. Slides were air-dried then stained using Dade $\mathbb{R}$ Diff-Quik (Gamidor Ltd, Oxon, UK) in order to determine differential cell count. At least 500 positively stained, nucleated nonsquamous cells were counted. Samples were considered adequate for analysis if there was $<7.5 \%$ squamous cell contamination.

\section{Analysis of positron emission tomography scans}

Using image analysis software [14], regions of interest (ROIs) were drawn over the right and left lung, excluding hilar structures, on the images of regional density reconstructed from the corresponding transmission scan (fig. 1), for all planes containing lung (between eight and 14, depending on the distance between the dome of the diaphragm and the lung apices). Quantification of radioactivity from these ROIs was obtained for the transmission scan in order to calculate lung density and for the subsequent emission scan or scans to calculate uptake of radioactivity.

For each ROI, the following parameters were calculated.

An index of glucose metabolic activity in the lung regions was quantified as the slope of a Patlak plot constructed from the tissue:plasma radioactivity of lung ROIs and venous blood radioactivity [15] (examples shown in fig. 2). The intercept of this plot represents the volume of tissue into which the ${ }^{18} \mathrm{FDG}$ is distributed. In order to estimate the uptake of ${ }^{18}$ FDG by the lung tissue, the calculated slopes were corrected for this initial distribution [6].

Regional thoracic density $\left(\mathrm{g} \cdot \mathrm{cm}^{-3}\right.$ of thorax) was calculated from the attenuation of radioactivity from the external ring source, transmitted through the chest during the initial transmission scan, in an identical manner to radiograph computed tomography.

Regional blood volume ( $\mathrm{g}$ of blood $\cdot \mathrm{cm}^{-3}$ of thorax) was calculated from the attenuation-corrected radioactivity measured following $\mathrm{C}^{15} \mathrm{O}$ breathing and the radioactivity measured in discrete blood samples taken during the scan, as follows:

$\left(\mathrm{C}^{15} \mathrm{O}\right.$ counts $\cdot \mathrm{cm}^{-3}$ of $\left.\mathrm{ROI}\right) /\left(\mathrm{C}^{15} \mathrm{O}\right.$ counts $\cdot \mathrm{g}^{-3}$ of blood $)$

Regional extravascular PK11195 concentration.g tissue ${ }^{-1}$ was calculated for each time frame from the ${ }^{11} \mathrm{C}-\mathrm{PK} 11195 \mathrm{ROI}$ counts, the ${ }^{11} \mathrm{C}-\mathrm{PK} 11195$ blood counts and the regional blood
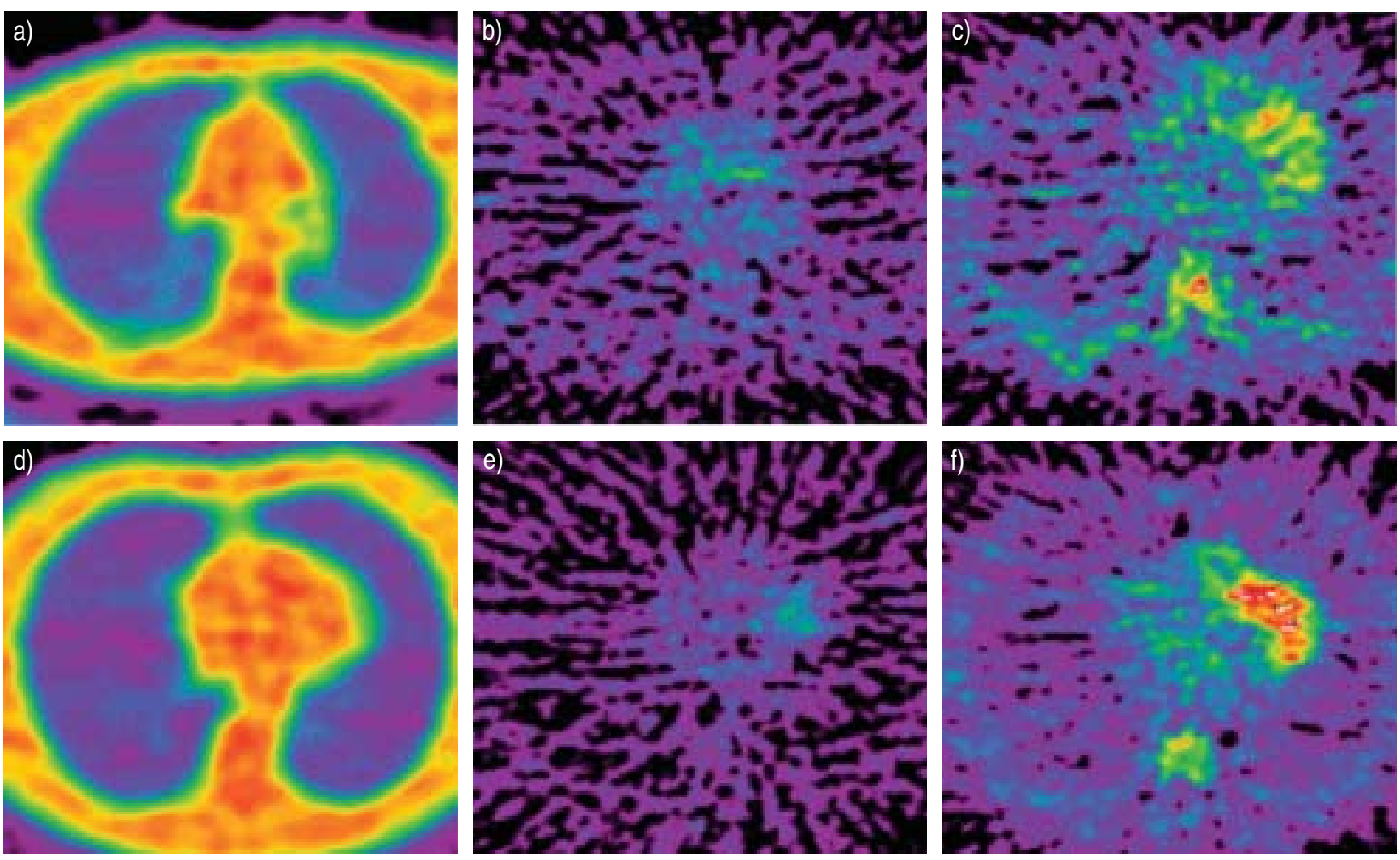

Fig. 1. - Transaxial thoracic images for transmission (a and d), ${ }^{18} \mathrm{~F}$-fluorodeoxyglucose $\left({ }^{18} \mathrm{FDG}\right)$ emission (b and e) and ${ }^{11} \mathrm{C}$-PK11195 (c and f) in a normal subject $(\mathrm{a}-\mathrm{c})$ and a patient with chronic obstructive pulmonary disease $(\mathrm{d}-\mathrm{f})$. The lung outlines are clearly seen in the transmission image, which is used to delineate the regions of interest for the analysis of the emission images. No obvious differences are seen between the patient and the normal subject in the emission images for either ${ }^{18}$ FDG or ${ }^{11}$ C-PK11195, due to the low density of the lung. Significant differences are only revealed by quantitative analysis of the acquired emission data. 


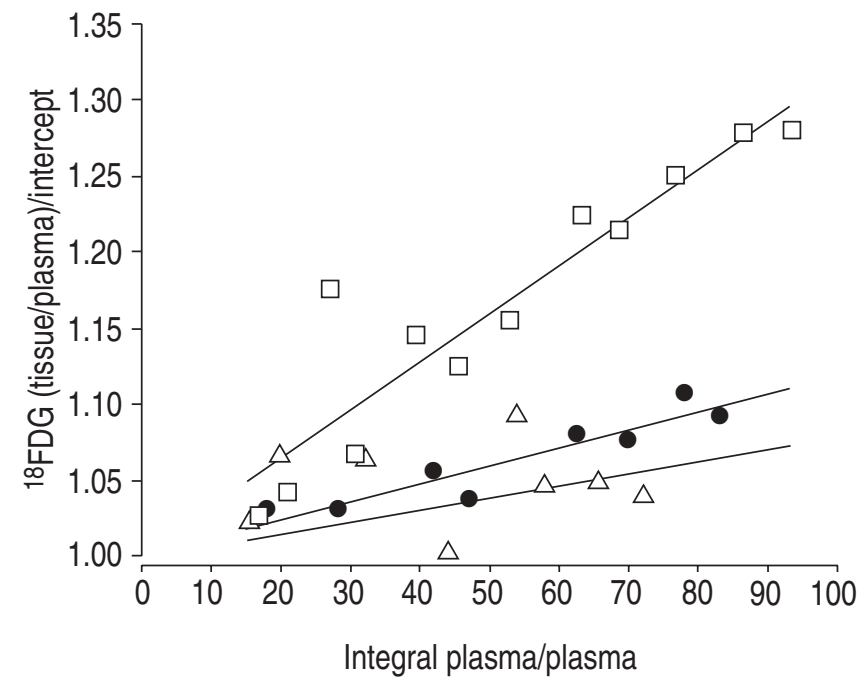

Fig. 2.-Examples of Patlak plots, normalised to intercept of 1.0, showing uptake of ${ }^{18} \mathrm{~F}$-fluorodeoxyglucose $\left({ }^{18} \mathrm{FDG}\right)$ in normal subject $1(-)$, chronic obstructive pulmonary disease patient 1 ( $\square)$ and asthma patient $1(\triangle)$. The data points are corrected for the initial volume of distribution of the ${ }^{18} \mathrm{FDG}$.

volume, as follows:

$$
\begin{aligned}
& \text { PK11195 concentration } \cdot \mathrm{g}^{-1} \text { tissue }= \\
& \left({ }^{11} \mathrm{C}-\mathrm{PK} 11195 \text { counts } \cdot \mathrm{cm}^{3}\right) / \text { density }
\end{aligned}
$$

Extravascular PK11195 concentration $\cdot \mathrm{g}$ of tissue $\mathrm{e}^{-1}=$ total PK11195 concentration-

(blood volume $\times$ blood PK11195 concentration)

Extravascular tissue:plasma was plotted to assess PK11195 uptake.

\section{Statistics}

Data were expressed as mean \pm SEM. Comparisons were made using the two-tailed t-test or one-way analysis of variance with the Tukey post hoc test, as appropriate. A $\mathrm{p}$-value of $<0.05$ indicated statistical significance.

\section{Results}

Smoking history and baseline lung function tests are set out in table 1 . All patients were taking short-acting $\beta_{2}$-agonists and three COPD patients were taking long-acting $\beta_{2}$-agonists compared with one asthmatic. All the COPD patients and five of the asthmatics were taking an inhaled corticosteroid. The mean dose of inhaled corticosteroid was $1,560 \mu \mathrm{g} \cdot \mathrm{day}^{-1}$ (beclomethasone or equivalent) in the COPD patients and $1,200 \mu \mathrm{g} \cdot \mathrm{day}^{-1}$ in asthmatics. There was no significant difference in terms of dose between the two patient groups $(\mathrm{p}>0.1)$.

Representative Patlak plots from a normal subject, a patient with COPD and an asthmatic patient are shown in figure 2. The rate of uptake of ${ }^{18} \mathrm{FDG}$ was clearly elevated in the patient with COPD relative to the normal subject. There was no detectable increase in ${ }^{18}$ FDG uptake in the patient with asthma.

Time activity plots for ${ }^{11} \mathrm{C}-\mathrm{R}-\mathrm{PK} 11195$ uptake for the same three subjects are shown in figure 3 . In all subjects the

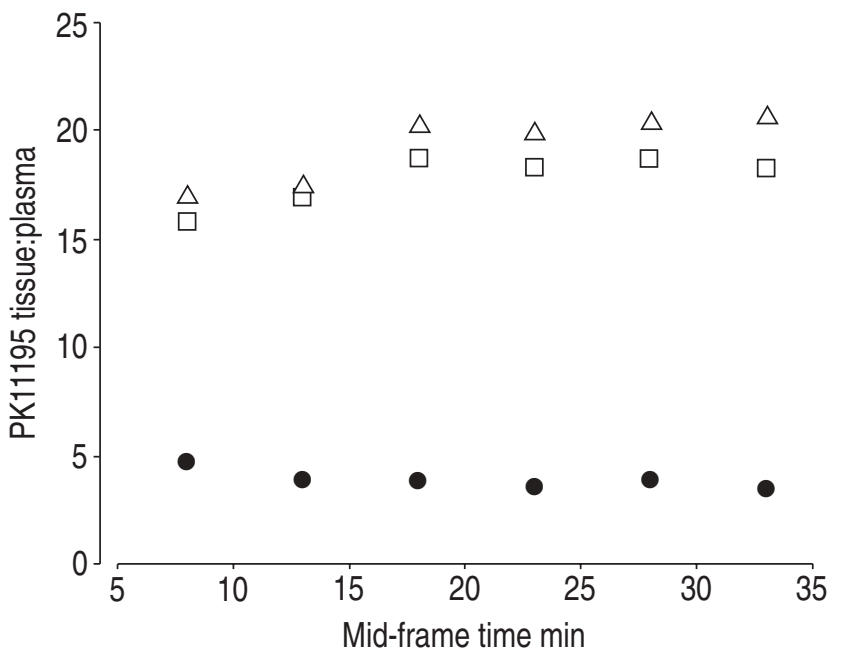

Fig. 3. - Examples of uptake of the ligand ${ }^{11} \mathrm{C}-\mathrm{PK} 11195$ for the same patients whose ${ }^{18} \mathrm{~F}$-fluorodeoxyglucose data are shown in figure 2. Normal subject $1(\bullet)$, chronic obstructive pulmonary disease patient $1(\square)$ and asthma patient $1(\triangle)$. These data points are the calculated extravascular tissue:plasma ratios for the last six time frames and demonstrate that a stable plateau is reached during the acquisition time.

tissue:plasma ratio reached a plateau by $20 \mathrm{~min}$, which was raised in the COPD and asthma patients.

Figure 4 shows the ${ }^{18}$ FDG signals for the three patient groups. ${ }^{18}$ FDG uptake in the COPD group was significantly higher than either the normal subjects $(p<0.001)$ or the asthmatic group $(\mathrm{p}<0.001)$.

There was no difference between the asthmatic group and the normal controls $(p>0.05)$. The uptake of the ligand ${ }^{11}$ C-PK11195, shown in figure 5 , had a wide variability within each patient group. Hence, the difference between the patient groups and the controls did not achieve significance $(\mathrm{p}=0.08)$. Nevertheless, individual PK11195 uptake values for three of the five asthmatic subjects and three of the six COPD subjects were above 3 SDs of the mean value for the normal control subjects.

PET scanning of PK11195 was not possible in one of the asthmatic subjects due to failure of the synthesis of the radiolabelled ligand. Values for individual and mean PET data for all subjects are shown in table 2 .

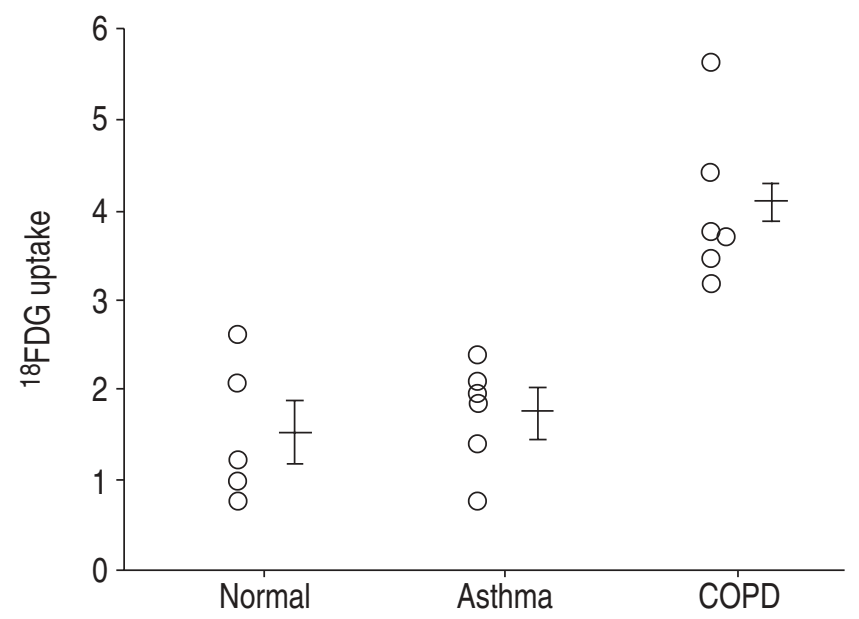

Fig. 4. - Individual values for ${ }^{18} \mathrm{~F}$-fluorodeoxyglucose $\left({ }^{18} \mathrm{FDG}\right)$ uptake in the three groups. Mean \pm SEM bars are shown beside each group. COPD: chronic obstructive pulmonary disease. 


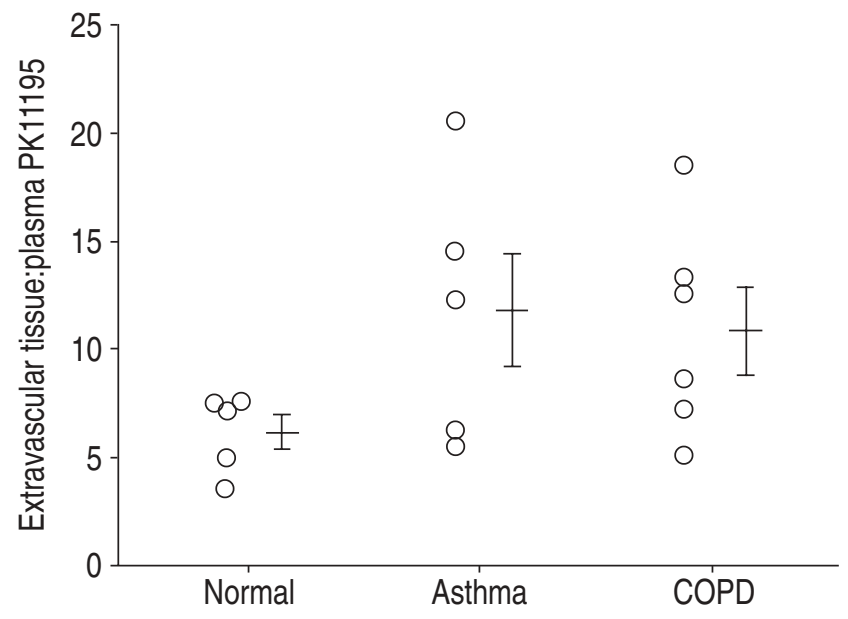

Fig. 5. - Individual values for ${ }^{11} \mathrm{C}-\mathrm{PK} 11195$ uptake in the three groups. Mean \pm SEM bars are shown beside each group. COPD: chronic obstructive pulmonary disease.

The total cell number per $g$ of sputum was higher in sputum samples from patient groups than controls $(\mathrm{p}<0.02)$. Total sputum neutrophils and eosinophils were increased in patients with COPD and in patients with asthma compared with controls, $\mathrm{p}<0.02$ in each case. There was no significant change in macrophage numbers. Sputum neutrophils were only $25 \pm 11 \%$ of the total cells in normal subjects but $71 \pm 8 \%$ in COPD and $48 \pm 7 \%$ in asthma. Eosinophils were also raised in patients $(7 \pm 3 \%$ in COPD and $11 \pm 4$ in asthma) in comparison to the normal group $(<1 \pm 0.3 \%)$. Values for individual and mean sputum cell counts are shown in table 2 .

\section{Discussion}

In this study it has been demonstrated that PET scanning may enable monitoring of the behaviour of two important cell types involved in the inflammatory response in the lung. Inappropriate activity of macrophages and neutrophils is known to be involved in a number of common lung diseases. The ability to study these cells in situ, without using invasive techniques or altering cell behaviour by ex vivo processing, is a major step forward. The current authors envisage that the application of this technique will allow monitoring of inflammatory cell activity in the lungs of patients with COPD and asthma. The current data also suggest marked differences in the nature of the inflammatory response between patients with COPD and asthma, consistent with invasive studies [16]. The technique should elucidate differences in the lung inflammatory response in these diseases and provide a useful surrogate marker of new treatments targeted at modulation of inflammation.

Despite the promise of this technique to monitor inflammatory cell activity in lung disease, these results should be regarded as preliminary, since patient groups were small. Although the COPD group of patients is well characterised, the group of asthmatics may be unusual in that they represent a more heterogeneous group and predominantly represent an asthmatic phenotype characterised by a degree of fixed airflow obstruction and sputum neutrophilia. Nevertheless, significant differences were observed, despite the small sample sizes, which indicate the power of this technique. The authors' data support the need for a systematic evaluation of PET scanning for the noninvasive monitoring of inflammation in common lung diseases.

In this pilot study, PET scanning revealed distinct

Table 2. - Uptake of ${ }^{18} \mathrm{~F}$-fluorodeoxyglucose $\left({ }^{18} \mathrm{FDG}\right)$ and ${ }^{11} \mathrm{C}-\mathrm{PK} 11195$ measured by positron emission tomography (PET) together with cell counts obtained from induced sputum

\begin{tabular}{|c|c|c|c|c|c|c|c|c|c|}
\hline \multirow[t]{3}{*}{ Subject } & \multicolumn{4}{|c|}{ PET data } & \multicolumn{5}{|c|}{ Sputum cell counts } \\
\hline & \multicolumn{2}{|c|}{ Lung density $\mathrm{g} \cdot \mathrm{cm}^{-3}$} & \multirow[t]{2}{*}{ Patlak slope ${ }^{\#}$} & \multirow[t]{2}{*}{ PK uptake } & \multirow[t]{2}{*}{ Total $10^{6} \cdot \mathrm{g}$ sputum $^{-1}$} & \multirow[t]{2}{*}{$\mathrm{PMN} \%$} & \multirow[t]{2}{*}{ Eosin. \% } & \multirow[t]{2}{*}{ Macro. $\%$} & \multirow[t]{2}{*}{ Lymph. \% } \\
\hline & ${ }^{18}$ FDG day & PK11195 day & & & & & & & \\
\hline \multicolumn{10}{|l|}{ Normal } \\
\hline 1 & 0.26 & 0.26 & 1.2 & 3.6 & 1.36 & 25 & 0 & 71 & 0 \\
\hline 2 & 0.30 & 0.29 & 1.0 & 7.5 & 1.76 & 64 & 1 & 32 & 1 \\
\hline 3 & 0.27 & 0.27 & 2.6 & 7.6 & 0.81 & 0 & 0 & 100 & 0 \\
\hline 4 & 0.25 & 0.25 & 2.1 & 7.1 & 2.40 & 7 & 0 & 89 & 0 \\
\hline 5 & 0.32 & 0.30 & 0.8 & 5.0 & 1.44 & 27 & 0 & 71 & 0 \\
\hline Mean & 0.28 & 0.27 & 1.5 & 6.2 & 1.55 & 25 & 0 & 73 & 0 \\
\hline \multicolumn{10}{|l|}{ COPD } \\
\hline 1 & 0.23 & 0.18 & 3.2 & 18.5 & 4.16 & 62 & 11 & 26 & 0 \\
\hline 2 & 0.21 & 0.21 & 4.4 & 12.6 & 9.78 & 91 & 2 & 5 & 0 \\
\hline 3 & 0.18 & 0.17 & 3.7 & 13.3 & 11.84 & 84 & 6 & 10 & 0 \\
\hline 4 & 0.19 & 0.21 & 3.8 & 7.1 & 8.24 & 81 & 3 & 15 & 0 \\
\hline 5 & 0.27 & 0.30 & 3.4 & 5.0 & 3.52 & 71 & 1 & 25 & 0 \\
\hline 6 & 0.24 & 0.21 & 5.6 & 8.5 & 2.40 & 40 & 19 & 21 & 2 \\
\hline Mean & 0.22 & 0.21 & 4.0 & 10.8 & 6.66 & 71 & 7 & 17 & 0 \\
\hline \multicolumn{10}{|l|}{ Asthma } \\
\hline 1 & 0.29 & 0.30 & 1.8 & 20.5 & 3.59 & 39 & 9 & 50 & 1 \\
\hline 2 & 0.27 & 0.27 & 2.4 & 12.2 & 8.48 & 47 & 47 & 5 & 0 \\
\hline 3 & 0.32 & 0.33 & 0.8 & 14.6 & 4.32 & 67 & 1 & 30 & 1 \\
\hline 4 & 0.29 & & 1.4 & & 4.64 & 29 & 0 & 69 & 1 \\
\hline 5 & 0.40 & 0.42 & 1.9 & 6.2 & 1.92 & 58 & 8 & 33 & 0 \\
\hline 6 & 0.44 & 0.40 & 2.1 & 5.5 & 4.80 & 60 & 0 & 39 & 0 \\
\hline Mean & 0.34 & 0.34 & 1.7 & 11.8 & 4.63 & 50 & 11 & 38 & 1 \\
\hline
\end{tabular}

PMN: polymorphonuclear neutrophil; Eosin.: eosinophil; Macro.: macrophage; Lymph.: lymphocyte. "* corrected for the initial volume of distribution of the ${ }^{18} \mathrm{FDG} ;{ }^{\top}$ : extravascular tissue:plasma ratio. 
differences in ${ }^{18}$ FDG uptake between the different study groups. A raised uptake in all the patients in the COPD group indicated that there was significant metabolic activation of inflammatory cells. Based on the authors' previous experience, using cellular resolution micro-autoradiography of titrated deoxyglucose in a variety of scarring and nonscarring models of pulmonary inflammation, only neutrophils were labelled, even at times when the majority of inflammatory cells were macrophages [7, 8]. The present authors have recently shown in vitro that the deoxyglucose signal is raised in both primed and activated neutrophils and may reflect the polarisation and migrational status of these cells [9]. In both patient groups in this study there were increased numbers of neutrophils in the induced sputum, but there was a correlation with the PET signal of FDG only in the COPD group, implying a difference in neutrophil status. All of the COPD group were exsmokers, and the persistent sputum neutrophilia and elevated ${ }^{18}$ FDG signal is consistent with the observation that the inflammatory process persists in this group of patients despite smoking cessation [17]. Failure of inhaled corticosteroids to suppress neutrophilic inflammation in these patients is also well described [18]. Indeed, recent studies have demonstrated failure of long-term corticosteroids to alter the progression of COPD [19]. The assessment of efficacy of novel anti-inflammatory agents could be greatly expedited by the use of PET as a marker of neutrophilic inflammation.

In contrast, ${ }^{18}$ FDG uptake in the lungs of asthmatic patients was the same as in normal subjects, despite increased numbers of neutrophils in the sputum samples. Selection of asthmatic subjects ensured that almost all subjects had a degree of airflow obstruction as a consequence of chronic asthma, even though five out of six had never smoked. COPD and asthma patients were taking similar doses of antiinflammatory medication. The predominance of neutrophils in the induced sputum of asthmatics is consistent with severe persistent asthma [20]. The lack of ${ }^{18}$ FDG signal in the lungs of asthmatics, despite the variability in their degree of airflow obstruction, may be explained by differences in the main sites of inflammation in asthma and COPD. In asthma most of the pathological changes are found in airways, although parenchymal changes may also be present [21]. Indeed, WENZEL et al. [22] have demonstrated tissue neutrophilia in asthma. In contrast, in COPD, marked cellular changes are found in the parenchyma as well as airways [23]. The COPD patients in this study all had a reduction in the transfer coefficient for carbon monoxide, indicating the presence of parenchymal destruction by emphysema. A further explanation for the difference in ${ }^{18}$ FDG signal between the patient groups may be that, although increased numbers of neutrophils are present in the lungs, they are not significantly activated in this corticosteroid-responsive asthmatic group. Differences in the regulation of the inflammatory response in COPD and asthma and/or different responses to inhaled corticosteroid treatment are well recognised [18].

The ligand PK11195 has been shown by others to bind to receptors (peripheral benzodiazepine-like), which are present in large numbers in macrophages [24]. This ligand has been labelled with ${ }^{11} \mathrm{C}$ for PET and has been successfully used to demonstrate influx of macrophages into the brain following stroke [25]. Despite the presence of some binding sites for this ligand on resident lung macrophages, submucosal glands and airway epithelium [26], the current authors have shown that the time course of increased ${ }^{11} \mathrm{C}$-labelled PK11195 uptake, measured noninvasively by PET, mirrors the pulmonary accumulation of macrophages in rabbit lungs in response particulate challenge [9]. The lung uptake of PK11195 was more variable between patients. The signal was increased in a proportion of both the COPD (four of six) and asthmatic (three of four) groups relative to the normal controls. This increase did not correlate with either the magnitude of the ${ }^{18}$ FDG signal or the severity of disease, as measured by lung function tests. Although there was no correlation with sputum macrophages it is likely that the phenotype of the macrophages is different in different lung diseases [27] and that these phenotypes may have different binding capacities for the ligand. Further definition of macrophage phenotype and ex vivo PK11195 binding may help to elucidate this.

In conclusion, these preliminary studies show that positron emission tomography may provide an assessment of lung inflammatory cell activity in vivo, allow differentiation of patients with smoking-related chronic obstructive pulmonary disease and asthma, and may provide a potentially important marker of persistent lung inflammation in studies of antiinflammatory treatments aimed at preventing disease progression in chronic obstructive pulmonary disease.

\section{References}

1. Lopez AD, Murray CC. The global burden of disease. 1990-2020. Nat Med 1998; 4: 1241-1243.

2. National Institute of Health. Global strategy for asthma management and prevention. NHLBI/WHO workshop report. Bethesda, MD, National Heart Lung and Blood Institute, 1995. Publication number 95-3659.

3. Barnes PJ. Chronic obstructive pulmonary disease. $N$ Engl $J$ Med 2000; 343: 269-280.

4. Vignola AM, Chanez P, Campbell AM, et al. Airway inflammation in mild intermittent and in persistent asthma. Am J Respir Crit Care Med 1998; 157: 403-409.

5. Saverymuttu SH, Phillips G, Peters AM, Lavender JP Indium 111 autologous leucocyte scanning in lobar pneumonia and lung abscesses. Thorax 1985; 40: 925-930.

6. Jones HA, Sriskandan S, Peters AM, Pride NB, Boobis AR, Haslett C. Dissociation of neutrophil emigration and metabolic activity in lobar pneumonia and bronchiectasis. Eur Respir J 1997; 10: 795-803.

7. Jones HA, Clark RJ, Rhodes CG, Schofield JB, Krausz T, Haslett C. In vivo measurement of neutrophil activity in experimental lung inflammation. Am J Respir Crit Care Med 1994; 149: 1635-1639.

8. Jones HA, Schofield JB, Krausz T, Boobis AR, Haslett C. Pulmonary fibrosis correlates with duration of tissue neutrophil activation. Am J Respir Crit Care Med 1998; 158: 620-628.

9. Jones HA, Cadwallader KA, White JF, Uddin M, Peters AM, Chilvers ER. Dissociation between respiratory burst activity and deoxyglucose uptake in human neutrophil granulocytes: Implications for interpretation of 18F-FDG PET images. J Nucl Med 2002; 43: 652-657.

10. Jones HA, Valind SO, Clark IC, et al. Kinetics of lung macrophages monitored in vivo following particulate challenge in rabbits. Toxicol Appl Pharmacol 2002; 183: 46-54.

11. Pauwels RA, Buist S, Calverley PMA, Jenkins CR, Hurd SS Global strategy for the diagnosis, management and prevention of chronic obstructive pulmonary disease. NHLBI/ WHO Global initiative for chronic obstructive pulmonary disease (GOLD). Am J Respir Crit Care Med 2001; 163: 1256-1276.

12. Spanevello A, Migliori GB, Sharara A, et al. Induced sputum to assess airway inflammation: a study of reproducibility. Clin Exp Allergy 1997; 27: 1138-1144.

13. Pin I, Gibson PG, Kolendovicz R, et al. Use of induced sputum cell counts to investigate airway inflammation in asthma. Thorax 1992; 47: 25-29.

14. Robb RA, Hanson DP. A software system for interactive and quantitaive visualisation of multidimensional images. Phys End Sci Med 1991; 14: 9-30.

15. Patlak CS, Blasberg RG, Fenstermacher JD. Graphical 
evaluation of blood-to-brain transfer constants from multiple time uptake data. J Cereb Blood Flow Metab 1983; 3: $1-7$.

16. Barnes PJ. Mechanisms in COPD: differences from asthma Chest 2000; 117: 10S-14S.

17. Turato G, Stefano A, Maestrelli P, et al. Effect of smoking cessation on airway inflammation in chronic bronchitis. Am J Respir Crit Care Med 1995; 152: 1262-1267.

18. Keatings VM, Jatakanon A, Worsdell YM, Barnes PJ. Effects of inhaled and oral glucocorticoids on inflammatory indices in asthma and COPD. Am J Respir Crit Care Med 1997; 155: 542-548.

19. Burge PS, Calverley PMA, Jones PW, Spencer S, Anderson JA, Maslen TK. Randomised, double-blind, placebo controlled study of fluticasone propionate in patients with moderate to severe chronic obstructive pulmonary disease. The ISOLDE trial. BMJ 2000; 320: 1297-1303.

20. Jatakanon A, Uasuf C, Maziak W, Lim S, Chung KF, Barnes PJ. Neutrophilic inflammation in severe persistent asthma. Am J Respir Crit Care Med 1999; 160: 15321539.

21. Kraft M, Djukanovic R, Wilson S, Holgate ST, Martin RJ.
Alveolar tissue inflammation in asthma. Am J Respir Crit Care Med 1996; 154: 1505-1510.

22. Wenzel SE, Schwartz LB, Langmack EL, et al. Evidence that severe asthma can be divided pathologically into two inflammatory subtypes with distinct physiologic and clinical characteristics. Am J Respir Crit Care Med 1999; 160: 1001-1008.

23. Finkelstein R, Fraser RS, Ghezzo H, Cosio MG. Alveolar inflammation and its relation to emphysema in smokers. Am J Respir Crit Care Med 1995; 152: 1666-1672.

24. Zavala F, Lenfant M. Benzodiazepines and PK 11195 exert immunomodulating activities on a specific receptor on macrophages. Ann NY Acad Sci 1987; 96: 240-249.

25. Ramsay SC, Weiller C, Myers R, et al. Monitoring by PET of macrophage accumulation in brain after ischaemic stroke. Lancet 1992; 339: 1054-1055.

26. Mak JCW, Barnes PJ. Peripheral type benzodiazepine receptors in human and guinea pig lung: Characterization and autoradiographic mapping. J Pharm Exp Ther 1990; 252: 880-885.

27. Cambell DA, Poulter LW, du Bois RM. Phenotypic analysis of alveolar macrophages in normal subjects and in patients with interstitial lung disease. Thorax 1986; 41: 429-434. 